\title{
Diverse Universe: The Law of Equity ${ }^{*}$
}

\author{
Indira Y. Junghare \\ University of Minnesota, Minneapolis, Minnesota, USA
}

\begin{abstract}
Peaceful living has become increasingly difficult to attain in today's world of globalization, modernization, mechanization, and competition for existing resources on all levels. Conflicts and violence are intensified due to population explosion, food insecurity, climate change, ecological and economic disaster, political and religious differences, and wars over territories and scarce resources. Additionally, health concerns are increasing, which can be partially linked to our current chemical-oriented agricultural and industrial practices. Furthermore, diverse life species are endangered from habitat loss, urbanization, and farming. By losing natural land and native species, we are losing ecosystem diversity. In an era when our planetary existence is threatened, what are the world's communities doing to save our collective existence? This paper, based on India's intellectual traditions, proposes a conceptual model or a system of philosophy of three related categories - diversity, ethics, and peace-for understanding diversity and differences at all levels of existence, individual (biological), collective (socio-cultural), and planetary (cosmological). The main purpose is to make this interdisciplinary study part of an educational philosophy for the creation of civilized societies that will value all lives on the basis of equitability, and recognize ethics of dignity, respect, liberty, justice, and peace.
\end{abstract}

Keywords: philosophy, diversity, law, equity, metaphysics, ethics, liberty, peace

\section{Introduction}

In the 21st century, faced with population explosion, limited resources, downsizing, business takeovers, and mistreatment of the poor and minorities, all peoples need to understand the meaning of diversity in the universe. Creative power dwells in every entity, whether material, biological, cultural, or spiritual, and contributes to an all-inclusive and interdependent existence. Therefore, it is necessary to recognize and appreciate the utility of the diversity of peoples, cultures, animals, plants, and all elemental life, both perceivable and non-perceivable. Understanding and embracing diversity of life provides benefits to communities and businesses by leading to tolerant and peaceful co-existence, greater innovation, and improved productivity. It is important not to make workforce diversity a quota system. Rather, workforce diversity should provide a way of achieving synergy within an organization, unity in social life, and a stress-free, fear-free, and peaceful personal life. Synergistic benefits from diversity can be achieved through commitment to a sound value system of ethics of dignity, respect, liberty, justice, and education.

The first section of the article explains a theoretical framework and methodological approach for the development of the philosophy of diversity, which is pluralistic realism, with the epistemology and ethics that

\footnotetext{
*Acknowledgment: I thank Marina Challeen for her presentation of the paper at the 16th International Conference on Diversity in Organizations, Communities, and Nations, University of Granada, Spain, 27-29 July, 2016, and the preparation of the academic program book, Diversity-Ethics-Peace, September, 2016.

Indira Y. Junghare, Ph.D., Professor \& Research Scholar, University of Minnesota.
} 
follow contemporary theories of virtue. The second section discusses the need of understanding diversity of life - both biological and cultural. The third section describes diversity-related conflicts and violence with data analysis. The fourth section analyzes the concept of diversity in relation to time, space, nature's law of equity, and humanity's perception of the diverse world. The fifth section provides scientific justification and a brief view of the philosophy of diversity through metaphysics, epistemology, and ethics along with guiding principles - based on virtue epistemology and virtue ethics for they are required for the virtuous conduct of individuals and societies to reduce conflicts and violence at all levels of existence. The sixth and final section deals with the philosophy of diversity's implications and applications for education.

\section{Theoretical Framework}

This research and presentation is in the tradition of Indian philosophy. The term "philosophy" refers to the study of general and fundamental problems concerning matters such as existence, knowledge, values, reason, mind, and language (Teichmann \& Evans, 1999). In Indian languages, "philosophy" is defined as tatvajnan, which means "knowledge of life-governing principles".

\section{Methodological Approach: Philosophical Syncretism}

Indian philosophical tradition includes a study of both physics and metaphysics: cosmology, epistemology, ethics, logic, psychology, and philosophies of language, religion, and life in general. Indian philosophy is synthetic, as contrasted with Western philosophy, with its analytical approach to reality and experience. During the historical development of Indian civilization, the synthesizing tendency of the Indian mind brought into harmony religion and philosophy, knowledge and conduct, intuition and reason, humans and nature, and God and humans (Radhakrishnan \& Moore, 1957). This tendency of perceiving links in various aspects of life and creating unity in complex and vast diversity is of vital importance in today's world of conflicts, wars, and violence.

Science provided justification for modifying social orders. Men used scientific discoveries to support their power over women, and Europeans asserted on scientific grounds their superiority over the world's other peoples (Burns, 2001; Junghare, 2017). Indian philosophers as well as religious people reasoned that scientists, whether Western or Eastern, are limited in their power of knowing and analyzing the world of diversity, especially in the context of the evolutionary nature of life. Creation of values and creation of systems of ethics and morals were believed to be the responsibility of rational leaders.

After conquering physical time and space, humans are attempting to conquer the planets. Diverse cultures are converging. Political and social ideologies are becoming similar around the world. Differences will not completely disappear, but they will acquire secondary importance, and similarities will become more numerous (Raju, 1992). Universal ideals will have to be the same for all. It seems that there is a need for world philosophy and universal ethics.

Since every person in every country is not a philosopher or an educated elite, problems will have to be solved by leaders who will have to be equipped with world-perspectives reflective of world-philosophy. A philosophical system will have to be developed by each philosopher and by each culture in its own way, but with due recognition of all values of life upheld in different parts of the world (Raju, 1992).

\section{Development of an All-Inclusive Philosophy of Pluralism}

The history of Indian philosophy is not marked by the development of one school or system derived or 
descended from another but by the clarification and synthesis of ideas. Following the inclusive nature of this tradition, the method used is integrative, inclusive of metaphysics, epistemology, philosophy of mind, and ethics. This approach considers various aspects of life as integral parts of all beings and all things and furnishes a standard by which any tradition or philosophy and system of ethics can be judged.

The purpose of "knowledge creation" is to guide others through the discovery of new ideas in the context of traditional models or systems. The goal is to present a philosophical model for the betterment of life, for the removal of ignorance, and attainment of sound values: fairness, goodness, truth, liberty, justice, and peace. Therefore, the philosophy of diversity proposed here does not contradict other models but, rather, constitutes another perspective, which accommodates all ideas, concepts, and theories promoted by diverse Indian philosophical systems: universalism, unique individualism of particulars, non-dualism, naturalism, humanism, and all-inclusive cosmopolitanism. Essentially, the proposed philosophy's characteristic feature is the unity or oneness of planetary existence that is marked by diversity and difference and governed by the natural law of equity. It insists upon seeing the planet as a whole; it does not suggest the imposition of uniformity through suppression of cultural diversity, nor does it propose the abolition of regional or national autonomy. As mentioned earlier, the main purpose of developing this model philosophy is for the promotion of a system of relational ethics of dignity and respect for humanity. The philosophy of unique particulars, i.e., of diverse existents in this world and the universe, demands mutual recognition and respect for peaceful coexistence.

\section{Understanding Diversity of Life}

\section{Biological/Natural}

Diversity exists at all levels of life. At the cosmological level, the diverse universe operates according to natural laws, such as the law of gravity and the law of relativity. At the universal level, diversity arises from the evolutionary nature of life and is related to time and space. According to biologist Wilson $(1999,88)$, "the origin of species is simply the evolution of some difference-any difference at all - that prevents the production of fertile hybrids between populations under natural conditions. Natural selection is, then, the wellspring of biological diversity." Unfortunately, biological diversity is declining. Ninety-nine percent of all species that ever existed on earth are now extinct, and we are in the midst of one of the great extinction spasms of geological history (Wilson, 1999). The question arises: What is to be done to save the planet? Solutions require cooperation among professions previously separated in academic institutions and practical traditions.

All philosophers acknowledge that multicultural and multiethnic awareness is an important new feature of our times, which makes it necessary to examine the nature of all life and the surrounding environment with a broader and more inclusive perspective that takes into consideration history, evolution, and interdependence of individuals and societies. 


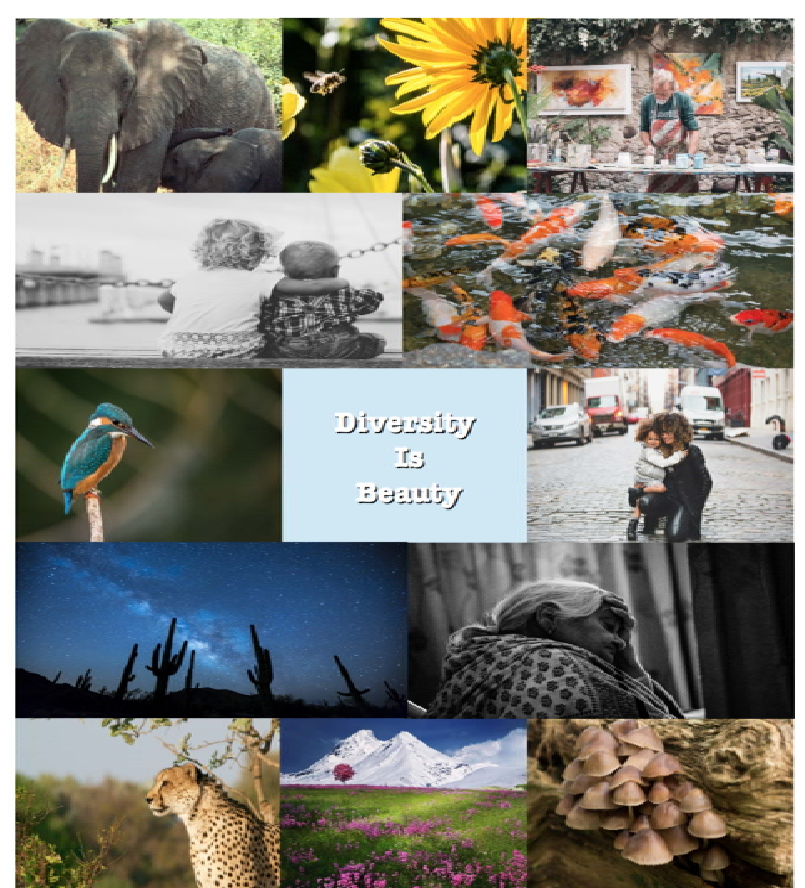

Figure 1. Diversity of life: biological and cultural (source: Challeen, 2016).

\section{Socio-Cultural}

Humans are social beings, belonging to diverse cultures. Despite membership in a particular cultural group, every person, regardless of origin, needs recognition and respect, sometimes at the expense of other things we value.

Understanding diversity requires recognizing, exploring, and celebrating differences in ways that move beyond mere tolerance to acknowledgement of the rich facets of diversity contained within each individual (Appiah, 2005).

In the 20th century, life, liberty and the pursuit of happiness were promoted in many nations and governments throughout the world as the result of many factors, including the Universal Declaration of Human Rights by the United Nations in 1948.

\section{Article 1}

All human beings are born free and equal in dignity and rights. They are endowed with reason and conscience and should act towards one another in a spirit of brotherhood.

Article 2

Everyone is entitled to all the rights and freedoms set forth in this Declaration, without distinction of any kind, such as race, color, sex, language, religion, political or other opinion, national or social origin, property, birth or other status. Furthermore, no distinction shall be made on the basis of the political, jurisdictional, or international status of the country or territory to which a person belongs, whether it is independent, trust, non-self-governing or under any other limitation of sovereignty.

If one's nation does not recognize a human's right to life, justice, peace, dignity, and self-determination, one would desire global citizenship. Thus, all-inclusive diversity refers to recognition of dignity in all members of diverse races, nations, societies, cultures, and ethnicities. 
Additionally, planetary diversity forces us to recognize all systems of elemental life for their contribution to the maintenance of our existence. Oceans, rivers, and mountains, along with animals and plants, need to be recognized for their utility. Implicit in this is a suggestion that all members of the planet, individuals, social organizations, communities, and nations take responsibility in addressing social, political, economic, and environmental issues. This proposition is in accord with the changes that are taking place in the world. For example, the government of India has recently passed a law that recognizes the right of the Ganga [Ganges] river to exist in efforts of protecting and restoring the ecosystem, as her water has been overused and has brought her existence into peril of extinction (Junghare, 2017).

Unfortunately, despite diversity, differences often cause conflict. Problems related to the diversity of gender, race, ethnicity, age, and class are not innate to these cultural categories as such but caused by prejudice, bias, misunderstanding, and ignorance.

Language communicates, defines, describes, and categorizes; hence labeling can also create rigid systems. Such systems are often problematic. For example, some transgender people are sometimes harassed by other members of the LGBTQ community if they don't choose to undergo surgery when they transition. They are labeled as "fakes" if they are not actively trying to "pass" as the gender that they are transitioning to (Huston \& Mussack, 2012). Harm ensues not only because transgender people are being excluded within their own community, but also because rigid labels reinforce the idea that there is no room for diversity. Even the pro-LGBT lawmakers believed that protecting transgender people was too radical for the bill to be passed, and gender identity was removed from the Employment Non-Discrimination Act (Weiss, 2003). Thus, these people remain unprotected inside and outside the LGBTQ community. Clearly, the example shows how important it is for diversity to be widely and correctly understood as something that is natural and something that is invaluable not only to people but to all life (Junghare, 2009).

\section{Diversity-Related Problems: Conflict and Violence}

Scholarly research has shown that a more diverse workforce creates a stronger environment for work. Sometimes, however, diversity becomes forced into a rigid quota system. Having a diverse workforce is an important goal that must not be forced. Trying to increase diversity by meeting a quota is not fostering true diversity; it is just adding tension and potential conflict to the workplace (Varvel, 2000).

Most industries, businesses, and governmental organizations are engaged in "properly" managing cultural diversity. Some companies have managed diversity well by taking advantage of different ideas and assets that people of various cultures bring with them. Since there is no textbook answer on how to properly manage diversity, most companies and organizations face difficulties of a diverse workforce (Varvel, 2000).

Diversity is sometimes misunderstood as another affirmative action program. Affirmative action is essentially "proportional representation for women and minorities" (Lynch, 1997, 12). Scholars such as Varvel (2000) have pointed out that diversity is not an affirmative action program and that a change must occur in the culture of the organization in order to embrace diversity. In the 1970s, major corporations and government agencies and universities embraced affirmative action programs. By the 1990s, a new field in the business world was being created, the field of diversity management (Loden \& Rosener, 1991; Varvel, 2000). Varvel (2000), from the United States Office of Personnel Management's Managing Diversity Participant workbook, states that diversity is the hardest and most challenging work because valuing and managing diversity touches people's emotions, values, and beliefs. It requires questioning and changing of policies, systems, and practices. 
There are many obstacles to creating a culture that values diversity. People fear change and do not wish to share the tightly-held power that leadership provides. It will take a long time to change the policies, systems, and practices that have been in place for years and destroy the cultural biases that diverse people bring with them (Varvel, 2000). Ultimately it is all reduced to equality and fair treatment perceived by those whose diversity falls outside the norm of the culture of the majority, either in an organization or the society. Since the Civil Rights Act was passed in 1965, the United States has made advances in racial tolerance. However, conflicts and violence have become common in recent years. The following examples serve as data in the illustrations of modern socio-cultural disturbances.

The following table on violence in the US provides a window to the problems related to inter-group relations stemming from diverse factors and phenomena: mental health, and biases and prejudices related to the diversity of races, gender, religion, and ethnicity.

Table 1

Violence Arising from Diverse Causes and Motives

\begin{tabular}{|c|c|c|c|c|c|c|}
\hline People shot/killed & Place & Date & Instrumental cause & Agential cause & News-sources & Root cause \\
\hline $\begin{array}{l}\text { Killed: } 12 \\
\& \text { injured } 70\end{array}$ & $\begin{array}{l}\text { Aurora, } \\
\text { Colorado: } \\
\text { Movie-Theater- } \\
\text { shooting } \\
\end{array}$ & 7-20-2012 & $\begin{array}{l}\text { Express tactical } \\
\text { shotgun \& } \\
\text { Semi-automatic rifle }\end{array}$ & A gunman & $\begin{array}{l}\text { The Denver Post } \\
\text { CBS News \& } \\
\text { Wikipedia }\end{array}$ & Mental-illness \\
\hline $\begin{array}{l}\text { Killed: } 20 \\
\text { school-children: } \\
6-7 \text { yrs of age } \\
\& 6 \text { adults } \\
\end{array}$ & $\begin{array}{l}\text { Newtown, CT: } \\
\text { Sandy } \\
\text { Hook-Elementary } \\
\text { School-shooting }\end{array}$ & $\begin{array}{l}12-14-201 \\
2\end{array}$ & $\begin{array}{l}\text { Bolt-action rifle } \\
\text { Bushmaster rifle }\end{array}$ & A gunman & $\begin{array}{l}\text { NBC News \& } \\
\text { Wikipedia }\end{array}$ & Mental-illness \\
\hline $\begin{array}{l}\text { Killed: } 49 \& \\
\text { wounded } 53\end{array}$ & $\begin{array}{l}\text { Orlando, Florida: } \\
\text { Gay Night club } \\
\text { shooting }^{3}\end{array}$ & $6-12-2016$ & $\begin{array}{l}\text { Sauer semi-automatic } \\
\text { rifle } \\
\text { Semi-automatic pistol }\end{array}$ & $\begin{array}{l}\text { Shooter } \\
\text { (Muslim) for his } \\
\text { religion }\end{array}$ & $\begin{array}{l}\text { Miami Herald } \\
\& \\
\text { Wikipedia }\end{array}$ & \begin{tabular}{|l} 
Gender \\
Religion \\
Violence against \\
LGBT \\
\end{tabular} \\
\hline \begin{tabular}{|l|}
$\begin{array}{l}\text { Killed: } 1 \text { black } \\
\text { man }\end{array}$ \\
\end{tabular} & \begin{tabular}{|l|} 
Falcon Heights \\
Minnesota $^{4}$ \\
\end{tabular} & $7-5-2016$ & Police rifle & $\begin{array}{l}\text { Shooter } \\
\text { (Police) }\end{array}$ & \begin{tabular}{|l|} 
Facebook-Video \\
Fox 9 News
\end{tabular} & $\begin{array}{l}\text { Race } \\
\text { Abuse of Power }\end{array}$ \\
\hline $\begin{array}{l}\text { Killed: } 5 \text { police } \\
\text { officers } \\
\text { Wounded: } 7 \\
\text { police and } 2 \\
\text { civilians }\end{array}$ & Dallas, $\mathrm{TX}^{5}$ & 7-7-2016 & Semi-automatic rifle & $\begin{array}{l}\text { Shooter } \\
\text { (Black man) }\end{array}$ & $\begin{array}{l}\text { The New York } \\
\text { Times \& } \\
\text { The Dallas } \\
\text { Morning News \& } \\
\text { Wikipedia }\end{array}$ & \begin{tabular}{|l} 
Race \\
Retaliatory \\
Violence
\end{tabular} \\
\hline
\end{tabular}

\footnotetext{
${ }^{1}$ Brown, Jennifer (July 21, 2012). "12 shot dead, 58 wounded in Aurora movie-theater during Batman premier." The Denver Post. Colorado movie theater massacre, CBS News, accessed 15 April 2018, https://www.cbsnews.com/feature/colorado. "2012 Aurora Shooting." Wikipedia, last edited 27 March 2018, https://en.wikipedia.org/wiki/2012_Aurora_shooting, accessed 21 July 2016.

2 Tracy, James F. (September 26, 2014). "The Sandy Hook School Massacre: Unanswered questions and missing information." Global Research, accessed 15 April 2018, https:www.globalresearch.ca/the-sandy-hook-school-masscre-unanswered questions-and missing information-2/5404355. Sandy Hook Elementary School shooting (2012): Wikipedia, last updated 17 April 2018, https://en.wikipedia.org/wiki/Sandy_Hook_Elementary School_shooting, accessed 25 April 2018.

${ }^{3}$ Rothaus, Steve (June 12, 2016). "Pulse Orlando shooting scene a popular LGBT Club where employees, patrons "Like Family.", Miami Herald, accessed 22 April 2018, www.miamiherald.com. Orlando nightclub shooting, Wikipedia, last edited 17 April 2018, https://en.wikipedia.org/wiki/2016_Orlando_nightclub_shooting, accessed 22 April 2018.

4 "Facebook-video shows aftermath of police shooting in Falcon Heights, Minnesota." 2016. http://www.fox9.com/news/170568861-story. "Shooting of Philando Castile." Wikipedia, last edited 12 April 2018 , https://en.wikipedia.org/wiki/Shooting_of_Philando_Castile.

${ }^{5}$ Fernandez, Manny, Richard Perez-Pena, \& Jonah Engel Bromwich (July 8, 2016). "Five Dallas officers were killed as Payback, police chief says.” New York Times, https://www.nytimes.com/2016/07/09/us/dallas-police-shooting.html. Pool, Smiley (July 8, 2016). "The Dallas police officers killed at protest.” Dallas Morning News, https://en.wikipedia.org/wiki/2016, accessed 22 July 2016.
} 
(table 1 continued)

\begin{tabular}{|l|l|l|l|l|l|l|}
\hline People shot/killed & Place & Date & Instrumental cause & Agential cause & News-sources & Root cause \\
\hline $\begin{array}{l}\text { Killed: 3 police } \\
\text { officers \& } \\
\text { wounded 3 }\end{array}$ & $\begin{array}{l}\text { Baton Rouge, } \\
\text { Louisiana6 }\end{array}$ & 7-17-2016 & $\begin{array}{l}\text { AR-15 } \\
\text { Semi-automatic rifle }\end{array}$ & $\begin{array}{l}\text { Shooter (Black } \\
\text { man) }\end{array}$ & New York Times & $\begin{array}{l}\text { Retaliatory } \\
\text { Violence }\end{array}$ \\
\hline
\end{tabular}

Sources: Details in end notes.

The table indicates that violent conflicts arise between people of diverse cultures, races, religions, genders, and nationalities. However, a more proper study of diversity can unveil deeper underlying causes. Understanding these deeper causes can lead to mutual respect and better relations between diverse cultures.

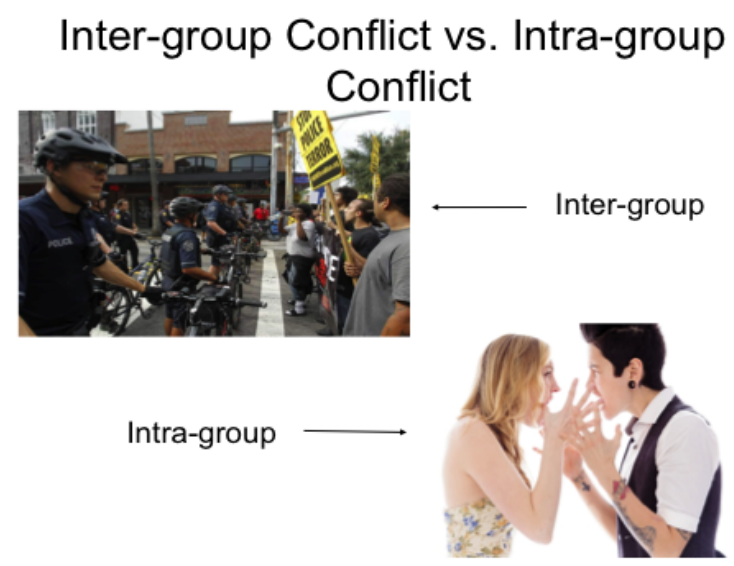

Figure 2. Source: Challeen, 2016.

\section{Analysis of the Data}

The data as categorized above into agential and instrumental causes show that conflicts and violence arose as a result of individual traits (mental illness and disrespectful, revengeful, and troubled mindset, or misuse of power) combined with cultural attributes (biases, prejudices, intolerance, and ignorance). What is common to these violent events? An appeal for fairness, equality, and dignity is common to these violent events. Every individual wants to be recognized and respected regardless of who he/she is and what culture he/she belongs to and what world-view he/she holds. Intercultural and intra-cultural conflicts are parts of life in any parts of the world. In the face of conflicts, wars, and violence, it becomes necessary to promote awareness of how every culture and individual deserves respect for unique contributions to all life's interdependent existence.

\section{What Diversity Entails}

Diversity has been described above as biological, cultural, universal-planetary, interconnected, and interdependent. Cultural diversity refers to differences in age, ethnic heritage, gender, national origin, marital status, immigration status, physical ability/qualities, race, religion, economic status, education, and sexual orientation (Schein, 2010, 9). Two other categories, caste and class, also form a part of "diversity".

Diversity extends beyond social constructs of color, gender, religion, class, caste, and status into an inherently dignified individual existence, wherein no one is superior since every being contributes to the web of

6 Blinder, Alan (July 18, 2016). "The 3 officers killed in Baton Rouge." New York Times, https://www.nytimes.com/2016/07/19/us/the-3-officers-killed-in-baton-rouge.html. "2016 shooting of Baton Rouge police officers." Wikipedia, updated on 5 April 2018, https://en.wikipedia.org/wiki/2016_shooting_of_Baton_Rouge_police_officers. 
being with unique talents, but every being is allowed to be itself. There is no norm in nature; there is no "better". Diversity entails accepting, appreciating, celebrating, and enjoying differences in everyone because in the vast diversity of the universe they are embedded similarities. Nature has created commonalities unifying the cosmos. The following quotation from a diversity studies student supports such a perception:

I consider myself a person, with many different backgrounds and opinions, and if I wanted someone to accept me via diversity, I don't want them to accept me as an American (because that's just looking through a small window and missing the big picture), but to just accept me as a person, with no boundaries on who I am. (Abebe, 2011, p. 2)

It is clear that the person Abebe perceives himself to be uniquely different and wants to be recognized for the multiple attributes of his character.

\section{Inclusive of Evolutionary Constructs}

Social constructs constantly change. "Race", interpreted to mean common descent, was introduced into English in about 1580, from Old French. According to Snowden (1983), ancient cultures did not discriminate against black people because of their color, and the overall view of blacks was favorable. Individuals with varying physical appearances became full members of a society by growing up within that society or by adopting that society's cultural norms. Snowden's research (1983) provides support to the evolutionary nature of socio-cultural ideas and practices.

During the 16th, 17th, and 18th centuries, scientists attempted to classify Homo sapiens based on a geographic arrangement of human populations according to skin color. Other classifications used geographic location, shape, stature, food habits, and other distinguishing characteristics. The term race was occasionally used, but early classifications also employed categories such as "peoples", "nations", "types", "varieties", and "species".

Modern evolutionary theory connects the evolving nature of life and the diversity stemming from it (Wilson, 1999). Darwin (1871) noted the diversity of differences and, on the basis of similarities, argued for continuity between humans and animals. Evolution connects genetic-cultural diversity with biodiversity. Thus, the concept of diversity has become broader. In light of biological and cultural evolution, in time and place and socio-political-religious environments, the concept of diversity has become complex and difficult to define. Therefore, there is a need to develop a system of philosophy that is inclusive of all life's being, becoming, and behaving. "All" life means all existents, substantive or spiritual, and their diverse forms related to time and space, and their equitable conservation for the health of the planet.

\section{The Law of Equity}

What is law? The Merriam-Webster Dictionary defines "law" as a statement of fact deduced from observation, to the effect that a particular natural or scientific phenomenon always occurs if certain conditions are present. In philosophy, "law" indicates a statement that describes invariable relationships between phenomena; for example, "where there is smoke, there is fire". In linguistics, an example of a law is: "voiceless consonants become voiced between voiced vowels". Similarly, there is an invariable relationship between forms of beings and their function. That is to say: Birds of a feather fly together. In the socio-cultural context, the Merriam-Webster Dictionary defines "law" as a rule of conduct or procedure established by custom, agreement, or authority.

According to the Indian philosophical view, the cosmos is ordered by natural laws, yet every being is uniquely distinct and permitted the needed freedom to function comparable to its form. 
What is equity? The concept of equitability, meaning "fair, just, and right," was extended by Indian writers of the Vedas and the Upanishads (1500-800 B.C.) in order to promote philosophical relativism and ethical humanism for allowing everyone freedom for rightful living. These texts tell us that all knowledge, experiences, and needs are relative to individuals and cultures. All depends on one's stance (MacGregor, 1989). Different things are important to different people translates to ethical relativism. Different identities are differently valued by individuals. "That one may win rule, another fame, another his desire, another achieve his end, to behold their different livelihoods the Dawn has awakened all living things", I. 113 (Thomas) (Radhakrishnan \& Moore, 1957, 31).

\section{Diverse Perceptions}

The word diversity in modern Indian languages such as Marathi and Hindi has two sources: bhinnata, "difference", and vividhata, "variety". The first meaning refers to a point of difference and the second refers to many-typed-ness. The focus is on differences - whether innate to life or instilled and developed by cultures and expressed through language constructs. In one sense, the concept of diversity refers to a state of being composed of differing elements (genetic or biological), while in another sense, it refers to identity in relation to objects in particular cultural categories. This ideology has been found in the Marathi speaker Anjira Mankar's holistic concept of diversity.

Diversity is the hallmark of life. No two things are exactly alike in size, shape, color, and pattern. Each and every thing has a purpose and function deserving of recognition and respect. It is the law of nature, incomprehensible and equitable. To sustain peaceful coexistence, the foundation of a civilized society, there is a need to recognize the value of every life; honor its dignity at all stages of survival; and truly understand diversity's beneficial contribution to all-inclusive societal, global, and planetary life. (Junghare, 1999, pp. 96-115)

The complexity of diversity forces societies to develop some mechanism for peaceful coexistence. Some societies use moral laws, while others make rules, policies, and laws in accordance with their beliefs and value systems. However, forced equality does not meet different needs. Those who do not form part of the majority become marginalized and victims of mistreatment. Table 1 and Figure 2 (above) have indicated the violent conflicts related to the complex nature of diversity on both levels - biological-genetic and cultural.

All people have different life experiences and different perspectives that make them who they are. Ignoring diversity of race, gender, ethnicity means disregarding unique experiences, backgrounds, and identities, which leads to disrespect and misunderstanding between people.

In reality, all people and all life forms are equally deserving of recognition and respect. This is the law of equity as it relates to diversity. The law of equity has been understood by scholars in the context of nature. The following quote indicates that nature appears to value individuality and difference:

To such an extent does nature delight and abound in variety that among her trees there is not one plant to be found which is exactly like another; and not only among the plants, but among the boughs, the leaves, and the fruits, you will not find one which is exactly similar to another-Leonardo Da Vinci. (Smiley \& Harp, 2017, pp. 78-79)

Nature does not discriminate against any life or the system to which it belongs. Moreover, all-inclusive life is marked by dependency and symbiotic relationships. Therefore, the philosophy of diversity proposed here respects the right of diverse beings to exist. 


\section{Foundations for a Philosophy of Diversity}

The universe is marked by diversity of all beings. Junghare (2009) advocates the need to go beyond controversies over origins because we can see only 4 percent of the universe; of the remaining 96 percent of the universe, 73 percent is dark energy and the remaining 23 percent dark matter (Elgin, 2009, 23).

The universe is constituted of matter. According to one theory of quantum mechanics, particles of matter are tiny strings of energy, and all existence is nothing but strings or energy points, which constantly vibrate. The nature of existence described by modern physicists in "string theory" was described by Buddhist philosophers of India as the theory of universal flux. Both scientific theory and philosophical theory provide different reasons for unity of diversity at the fundamental level. All existents are nothing but strings of energy (Junghare, 2010).

In the present era, it is often argued that there is no internal unity to metaphysics and that, therefore, metaphysics cannot be called a study or a discipline. However, personal identity of a Being can be investigated either in general or in relation to objects in particular categories, human, man, woman, dog, cat, plant, and bees. Drawing upon Indian intellectual traditions, an educational philosophy of all-inclusive diversity can be stated in the form of concise principles.

\section{Metaphysics-Epistemology-Ethics}

The proposed philosophical system of diversity is pluralistic realism, drawn from the Vaiśesika philosophy of "particulars", but combined with both materialistic and spiritualistic universalisms. Following the Vaiśesika system, the central claim of the proposed philosophy is that variety, diversity, and plurality are the warp and woof of reality; in other words, ultimate reality is constituted of irreducible particulars (Puligandla, 1975). In the context of quantum physics, the ultimate form of every particular is "energy", which becomes a part of the collective life of humanity and of the planet. The philosophy of diversity builds upon Vaiśesika's categories of objects that make up the world: substance, quality, action, generality, particularity, and inherence, but through some modifications and some additions of new categories, for example, the Vaiśesika category of substance includes time and space as non-material substances, whereas, the proposed philosophy gives them full categorical status since they contribute significantly to the creation of diversity. Additionally, suggested new categories are: equity, neutrality, distinctiveness, dependency, symbiotic relations, purpose, function, transformation, and change. These categories explain all kinds of evolutionary diversity and relational ethics.

Epistemology, a branch of philosophy, that investigates the origin, nature, methods, validity, and limits of human knowledge, serves as an instrument for understanding metaphysical categories and the world they represent. In an age of information technology, extreme capitalism, and excessive consumerism, this branch of philosophy is needed for teaching ethics of diversity, identity, aesthetics, authenticity, integrity, and respect. We face problems in knowing what information is, what analytical knowledge is, and what true knowledge is.

A contemporary philosophical approach to epistemology, known as virtue epistemology, claims to follow theories of virtue ethics, establishing the relations between epistemology and ethics. Both Western analytical tradition and Indian synthetic tradition have been engaged in efforts in solving problems of special concern by directing attention to the knower/thinker as agent similar to the way virtue ethics focuses on moral agents rather than moral acts.

It is difficult to have a single set of ethics for all societies because societies differ in beliefs and ways of life. The very word "ethics" implies "ethos". That means virtues are grounded in a particular time and space. 
However, some universal categories as part of epistemology and ethics of diversity include truthfulness, honesty, integrity, kindness, compassion, humility, authenticity, equanimity, and recognition of and respect for others. In presenting this list, the author faces the criticism of being labeled as a promoter of unsustainable utopianism because the diversity of cultures, beliefs, customs, and lifestyles cannot be in complete harmony.

Since the philosophical model of diversity has been developed for educational purposes, the philosophy needs to be idealistic for the production of civil citizens. As a philosopher of education, Page (2008) argues that virtue ethics can provide a rationale and foundation for peace education. Schools like the Intellectual Virtue Academy in Long Beach, California, build their pedagogy around cultivating intellectual virtues. More importantly, all people, including students, are products of their socio-cultural-intellectual environment. Education in ethics is bound to produce ethical personalities. Ethical characters are likely to make just societies.

\section{Philosophical Principles}

(1) Every being is different from another in form and content, i.e., in shape, color, pattern, and consciousness.

(2) All beings differ from each other in quantity and quality. Ultimate reality is constituted of particulars.

(3) All beings, observable or non-observable, are connected through symbiotic relationships forming a complex, layered existence, and sometimes called the "Web of Life" (Junghare, 2009).

(4) Every being is individually unique, contributing to the sustenance of the all-inclusive diversity of life. This important principle represents the Vaiśesika philosophical system of uniqueness of particulars or individual identity.

(5) Every being has the right to justice and freedom.

(6) No being can be defined, described, or understood fully (from the Vedanta philosophy).

(7) Diversity develops in the context of evolution in time and space (Wilson, 1999).

(8) Perception of diversity differs depending on where one stands (from Jaina philosophy).

(9) This philosophy of diversity combines substance and process philosophies (orthodox and heterodox).

(10) Diversity of life, though incomprehensible, forms a unified existence through commonalities and connectivity (Junghare, 2011).

\section{Ethics of Diversity}

Ethics is defined here as principles of virtuous conduct governing an individual or a group. The philosophy of diversity adheres to the following:

(1) Understanding diversity of life: both singularly and collectively, biologically and culturally, i.e., holistically.

(2) Dignity of Life: Following Kantian philosophy (Johnson \& Cureton, 2008), human life's value cannot be measured in relation to anything, e.g., economic utility. Every being has inalienable rights to life, liberty, and happiness.

(3) All democratic philosophies and most religions confirm the sanctity of life and require doing no-harm in thought, word, or deed.

(4) The philosophy of diversity demands that every being must be recognized and respected for its contribution to "all-inclusive" life.

(5) Respect for all beings, material or spiritual, leads to peace.

People are products of cultural experiences. Ignorance causes generalizations and forms stereotypes. The 
advantages of understanding diversity and differences and respecting every being as unique are too great to ignore. The key to valuing diversity is commitment on the part of leaders of educational organizations-schools, colleges, and universities. Cultural change does not come easily and requires setting specific goals, breaking from past practices, and communicating the desire for change.

\section{Implications and Applications for Education}

Earlier, we discussed one gender problem of diversity and the conditions that problematize it and its consequences. When misunderstood, diversity can promote bias and conflict, leading to violent confrontations. However, diversity-related issues can be resolved through education in the philosophy of diversity and ethics. Philosophy is broad and deals with diverse worldviews based on logical reasoning and personal experiences. Therefore, understanding diversity can create ideological conflicts. For a scholar of history or geography, any philosophical statement would be contentious. However, philosophy's multi-disciplinary nature provides scholars necessary freedom of thought to create knowledge and build scientific theories about life at various levels: individual-biological, socio-cultural, regional, global, universal, and cosmological.

Philosophers and theorists can educate leaders and help shape policies and laws needed for daily life. Creation of analytical knowledge and formulation of theories and their teaching and learning remain the subjects for consideration by educational institutions and community organizations. A strong foundation in ethics and the philosophy of diversity will foster a new generation of thoughtful global citizens who have been trained to recognize the value of diversity and how to use that knowledge to strengthen relationships.

We can develop academic programs and design diversity-ethics related curricula with pedagogical implications. Promotion of the philosophy of diversity and universal ethics can be done in three ways: (1) presenting students with societal issues and preparing them to become agents of change through community-service programs; (2) teaching students to see and understand the cosmos as one unified system with diverse regional and cultural manifestations and developing understanding and tolerance; (3) teaching the nature of relationships between the self and other members of the planet in accordance with a curriculum that attends to human values and a broad universal system of ethics.

The Honors Program of the University of Minnesota permitted the author to develop and teach a core curriculum of a dozen courses in the multidisciplinary studies of diversity-ethics-peace, complemented by courses in ethnic studies, socio-linguistics, feminist studies, gender and sexuality studies, cultural studies, global studies, comparative philosophies, and religions. The curriculum has been supported by advanced research in those disciplines.

The sample curriculum includes:

(1) Diversity of Life,

(2) Understanding Diversity: A Universal Perspective,

(3) You Are You: Philosophy of Diversity \& Difference,

(4) Aesthetics of Diversity,

(5) Ethics of Diversity,

(6) Languages and Social Identity,

(7) Communication Between Cultures,

(8) Bilingualism,

(9) Languages and Society, 
(10) Philosophies of Ethics \& Peace,

(11) Zen of Peace,

(12) Comparative Religious Philosophies.

To summarize, the law of equity, which is an important part of the philosophy of diversity, confirmed by the natural law of equity, and strengthened by ethics of identity, dignity, integrity, respect, and honor, can help promote peace and cooperation. The most important way this can be done is by building curriculum and introducing academic programs to students when they are young from age five to eighteen, i.e., during the time their characters are shaped so that the rest of their education and even their perspective on life will be developed by their ability to see the value of diversity in the world around them. Diversity may come with its own share of intrinsic problems, but the more one understands its value, the more one will be able to develop good relationships; and the more people will understand each other, the less conflict there will be in the world.

\section{References}

Abebe, T. (2011). Diversity. Language and Identity. Minneapolis, MN: University of Minnesota—Working Papers.

Appiah, K. A. (2005). The Ethics of Identity. Princeton, New Jersey: Princeton University Press.

Burns, W. E. (2001). The Scientific Revolution: An Encyclopedia. Santa Barbara, California: ABC-CLIO.

Challeen, M. (2016). Diversity-Ethics-Peace. Minneapolis, MN: University of Minnesota-Diversity, Ethics, Peace Club.

Darwin, C. (1871). The Descent of Man, and Selection in Relation to Sex (1st ed.). London: John Murray.

Elgin, D. (2009). The Living Universe. San Francisco, CA: Berrett-Koehler.

Huston, E., \& Mussack, S. (2012). Global LGBT Movements. Understanding Diversity. Minneapolis, MN: University of Minnesota-Working Papers.

Johnson, R., \& Cureton, A. (2008). Kant's Moral Philosophy. In E. N. Zalta (Ed.), Stanford Encyclopedia of Philosophy. Stanford University: Metaphysics Research Lab.

Junghare, I. Y. (1999). The Poetry Pond. Mumbai: Somaiya Publications.

Junghare, I. Y. (2009). Pluralism and Symbiotic Relationships: A Path to Peace. International Journal of Diversity in Organizations, Communities, \& Nations, 18(6), 41-56.

Junghare, I. Y. (2010). Biodiversity and Systems of Ethics. International Journal of Diversity in Organizations, Communities, \& Nations, 10(1), 25-38.

Junghare, I. Y. (2011). The Unified Universe: The Theory of Brahman. International Journal of Diversity in Organizations, Communities, \& Nations, 10(6), 15-28.

Junghare, I. Y. (2017). Diversity for Peace: India's Cultural Spirituality. Cultural and Religious Studies, 5(1), 1-16.

Loden, M., \& Rosener, J. B. (1991). Workforce America! Managing Employee Diversity as a Vital Resource. Homewood, IL: Business One Irwin.

Lynch, F. R. (1997). The Diversity Machine. New York: The Free Press.

MacGregor, G. (1989). Dictionary of Religion and Philosophy. New York: Paragon House.

Page, J. S. (2008). Peace Education: Exploring Ethical and Philosophical Foundations. Charlotte, NC: Information Age Publishing. Puligandla, R. (1975). Fundamentals of Indian Philosophy. Nashville, TN: Abingdon Press.

Radhakrishnan, S., \& Moore, C. (1957). A Sourcebook in Indian Philosophy. Princeton, New Jersey: Princeton University Press.

Raju, P. T. (1992). Introduction to Comparative Philosophy. Delhi: Motilal Banarsidass.

Schein, E. H. (2010). Organizational Culture and Leadership. San Francisco, CA: Jossey-Bass Publishers.

Smiley, N., \& Harp, D. (2017). Mindfulness in Nature. New York, NY: Hatherleigh Press.

Snowden, F. M. (1983). Before Color Prejudice: The Ancient View of Blacks. Cambridge, MA: Harvard University Press.

Teichmann, J., \& Evans, K. C. (1999). Philosophy: A Beginner's Guide. New Jersey: Blackwell Publishing.

United Nations. (1948). Universal Declaration of Human Rights. Retrieved from http://www.un.org/en/universal-declaration-human-rights/

Varvel, T. K. (2000). Ensuring Diversity is not just another Buzz Word. Alabama: Air University.

Weiss, J. T. (2003). GL vs. BT: The Archaeology of Biphobia and Transphobia within the U.S. Gay and Lesbian Community. Journal of Bisexuality, 3(3-4), 25-55.

Wilson, E. O. (1999). The Diversity of Life. New York: W. W. Norton \& Company. 